\title{
Editorial
}

\section{Adding to the Biology Education Research Tool Kit: Research Methods Essays}

\author{
Erin L. Dolan* and Elisa Stone ${ }^{\dagger}$
}

*University of Georgia, Athens, GA 30602; ${ }^{\dagger}$ University of California, Berkeley, Berkeley, CA 94720

\begin{abstract}
An increasing number of resources are becoming available to support the professional development of scientists transitioning to studying science education. For example, astronomy education researchers, Slater et al. (2010), offer practical advice for scientists who want to study science teaching and learning. Bunce and Cole (2008) provide similar guidance to those interested in chemical education. Josepha Kurdziel, Julie Libarkin, and others have published a handful of essays that summarize current knowledge in science education research for geologists and geology teaching audiences (National Association of Geoscience Teachers, 2008). Several organizations offer online or in-person guidance in designing classroom research studies or publishing education scholarship, one example being the American Society for Microbiology's Biology Scholars Program (www.biologyscholars.org), which prepares biologists to assess, study, and write about biology teaching and learning.

Yet the need for professional development in this area continues to outpace available resources. Many biologists who are experts in the research methods and norms of their discipline struggle to select appropriate research designs and methodologies when they want to study learning at their own institutions or in partnership with $\mathrm{K}-12$ schools and teachers. Recognizing the need for professional development, reviewers and the editorial board of CBE-Life Sciences Education (LSE) provide developmental feedback to authors prior to and during the review process. Such feedback includes offering guidance on the potential of the work and pointing out model publications or key references to improve the study design, data interpretation, and, ultimately, the quality of LSE manuscripts. This developmental approach to manuscript
\end{abstract}

DOI: $10.1187 /$ cbe.13-06-0109

Address correspondence to: Erin L. Dolan (eldolan@uga.edu).

(C) 2013 E. L. Dolan and E. Stone. CBE-Life Sciences Education (C) 2013 The American Society for Cell Biology. This article is distributed by The American Society for Cell Biology under license from the author(s). It is available to the public under an AttributionNoncommercial-Share Alike 3.0 Unported Creative Commons License (http:/ / creativecommons.org/licenses/by-nc-sa/3.0).

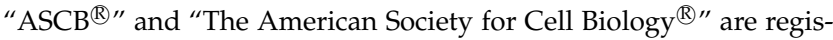
tered trademarks of The American Society for Cell Biology. evaluation has enhanced the capacity of the biology education community to conduct and publish exemplary research.

Despite these early gains, we receive manuscripts with significant methodological issues that slow or prevent the publication of interesting work or limit its usefulness. Biology education research will move forward if the biology community more fully understands the specific methodological issues encountered by individuals working at the intersection of biology and education. For example, what do social scientists mean by "theory" and "theoretical framing," and how can learning theories and other relevant knowledge be used to inform the design and interpretation of biology education research? What constitutes a case study, and why are case studies and other qualitative research traditions important for understanding teaching and learning? What are exemplary uses of mixed methods? What types of research questions or problems necessitate using experimental, quasiexperimental, and comparison studies? How can we measure learning and other important education-related variables in ways that are meaningful for making generalizable inferences? And why are the metrics we use every day to assess learning in our classrooms, such as exam scores and course grades, insufficient to accomplish this goal?

To help address broad questions, LSE is augmenting its professional development tool kit by launching a new type of essay, titled Research Methods. Essays on Research Methods will offer scholarly and practical advice on biology education research design and methods. These essays will serve as instructional pieces, identifying common and significant methodological issues. For example, an essay might explain how inappropriate approaches can undermine the value of the work and lead to erroneous interpretations and may go on to offer recommendations of more effective methods. Research Methods essays will "translate" social science approaches in ways that are compelling and approachable for trained biologists interested in education research. Essays might provide real and relatable examples of good practices or fictionalized examples written to illustrate central points. Comprehensive treatment of any methodology would be difficult in a single paper, so we expect Research Methods essays will be framed as starting points, steering readers to relevant references to learn more. 
The inaugural Research Methods essay in this issue is on the analysis of effect size, presented by Jessica Middlemis Maher, Jonathan Markey, and Diane Ebert-May. The authors define what effect size is: a measurement of the strength of a relationship between two variables or the size of a difference between two groups. The authors argue that differences such as student performance following two different types of instruction can be statistically significant but not meaningful in terms of learning. Calculating effect size is one way to gain insight into whether a statistically significant difference represents a meaningful difference in the classroom. The essay describes how effect size can be calculated, under what circumstances different effect size computations should be used, and what effect size means in an educational context. Throughout the essay, the authors direct readers to references that illustrate how their recommendations can be put into practice and that serve as references for in-depth explanations.

LSE invites submission of Research Methods essays. Essays should focus on a single topic, treating it with sufficient depth for readers to understand and be able to take action on the issue, while appealing to a broad audience of biology education scholars and educationinterested biologists. Although the manuscript should fit the general format for essays (see Information for Authors: www.lifescied.org/site/misc/ifora.xhtml), authors are encouraged to be creative. For example, Research Methods essays could be scholarly reviews punctuated by practical advice or in-depth discussions of articles that illustrate exemplary methodological practice. The essays should be concise and accurate yet approachable, clearly defining technical terms and using biology-friendly analogies and examples to illustrate key points. Coauthorship by social scientists and biologists is encouraged.

We predict that Research Methods essays will inspire biologists just beginning to work in the field of biology education research and add to the expertise of investigators who have been doing science education research for many years. We hope the essays will spur productive conversations about methodology in the biology education community, stimulate new collaborations, and ultimately improve biology teaching and learning.

\section{REFERENCES}

Bunce DM, Cole RS (eds.) (2008). Nuts and Bolts of Chemical Education Research, Washington, DC: American Chemical Society.

National Association of Geoscience Teachers (2008). Research in Science Education. www.nagt.org/nagt/jge/columns/methodologies .html (accessed 10 June 2013).

Slater SJ, Slater TF, Bailey JM (2010). Discipline-Based Education Research: A Scientist's Guide, New York: W.H. Freeman. 